\title{
Effects of Regenerated Sportive Activities on the Empathic Tendency of Women
}

\author{
Mehibe Akandere ${ }^{1}$, Fatma Arslan ${ }^{2}$, Evrim Cakmakci ${ }^{1}$ \\ ${ }^{1}$ Selcuk University, Faculty of Sports Sciences, Konya, Turkey \\ ${ }^{2}$ Necmettin Erbakan University, Faculty of Tourism, Department of Recreation Management, Konya, Turkey \\ Correspondence: Fatma Arslan, Necmettin Erbakan University, Faculty of Tourism, Department of Recreation \\ Management, Konya, Turkey.
}

Received: February 5, 2018

doi:10.11114/jets.v6i4.2983

\author{
Accepted: March 8, $2018 \quad$ Online Published: March 16, 2018 \\ URL: https://doi.org/10.11114/jets.v6i4.2983
}

\begin{abstract}
The purpose of this study is to determine the levels of empathy for regularly exercising women and to determine whether empathy levels differ according to some variables.

The study is planned as a single group pretest-posttest. 178 sedentary and healthy adult women participated in the study as a volunteer. Aerobic-Dance Exercise program was applied to the participants 60 minutes a day, 3 days per week for 8 weeks; then, The Empathic Tendency Scale (EQS) were filled at the beginning and at the end of the exercise program. The validity and reliability study of the scale was conducted by Dokmen (1988).

Statistical Package for Social Sciences (SPSS) 16.00 software was used in the analysis of the data obtained from the research. One way ANOVA was used to determine the differences between the groups when the data showed normal distribution and after the homogeneity of the variances was tested, the Tukey test was used for differences between the groups and the error level was taken as 0.05 .

When the findings are examined; the mean score of " Empathic Tendency " according to the marital status, the study status and the number of children of the participants was statistically significant in the pretest-posttest after the exercise program $(\mathrm{p}<0.005)$. But, there was no statistically significant difference between the group's comparisons in terms of the "Empathic Tendency "(p>0.05). As a result, it was seen that exercise had a positive effect on the "Empathic Tendency" levels of the women participating in the study.
\end{abstract}

Keywords: women, empathy, aerobic-dance, exercise

\section{Introduction}

The empathy, defined as the substitution of a person, in short, for the person in question, is considered as an important variable in the effective and healthy communication between people, and is often categorized as cognitive and emotional empathy (Davis, 1983a \& 1983b; Eisenberg \& Miller, 1987; Eisenberg \& Strayer, 1987; Smith, Keating \& Stotland, 1989).

Empathy as a term, being objectively aware of the thoughts and feelings of others and their possible meanings; means to live as a representative of the feelings and thoughts of the other person (Solak, 2011). Empathy is defined as the ability to understand the feelings of another person in general and the role of the other person as a psychological understanding without entering this role (Barut, 2004).

Empathy is a form of communication that makes sense to the other. This is essential in terms of being able to sustain the inevitable communication for the human being in a healthy way. The most substantial feature of empathic behavior is the distance from selfishness (Cetin, 2010). Sport is an important means of communication that allows for close and effective relationship formation if it is regularly, constantly and scientifically involved in the lives of individuals. Sport shortens social distances and improves social relations and requires both empathize and improve empathy habit.

Empathy is the ability to fully understand other people's behaviors and feelings through the use of imagination (Winnet, 2001). When one empathizes, s/he puts his/her own thoughts, analyzes and works away and begins to sense the other person and feel like the other person (Bellous, 2001). 
Kohlberg (1969) defined empathy as the process of taking another person's role or looking at from another person's perspective and he sees empathy as a cognitive phenomenon when he defines empathy as being related to Piaget and Mead (Reeves, Bowman \& Cooley, 1989; Roßnagel, 2004). Hogan (1969) defined empathy as empathy focusing on the cognitive direction of empathy and mentally perceiving the thought of the other as being in it. Feshbach and Roe (1968) have criticized empathy as cognitive, defining empathy as an emotional experience of a different part and giving emotional responses accordingly). According to Eisenberg and Strayer (1990), empathy is defined as the recognition of the emotional state of the opposite subject and giving a reaction to it in relation to the emotional state.

Especially, empathic skill in interpersonal relationships is considered as an important part of general communication skills (Barnett, 1990; Cuceloglu, 1994; Dokmen, 1995; Voltan \& Acar, 1994). Empathy is a way of putting a person in the face of his/her face in order to correctly understand his/her feelings, thoughts and the process of communicating this to him (Dokmen, 1995). In fact, research findings comparing the personality traits of high or low empathy adults in interpersonal relationships reveal that high empathy individuals have positive personality traits. It has been found that people with high empathic skills are the people who are loving, tolerant, and self-confident (Kalliopuska,1992).

There have been many studies on the impact of empathic skills in social relationships. However, research on the role of empathy in the sporting environment is almost non-existent (Erkus \& Yakupoglu, 2001). In a study of the relationship between empathy and self-esteem with active sport, (Kalliopuska, 1992) empathy was found to be an important variable in sports efficacy. In another study of the self-worth and narcissistic tendencies of Finnish baseball players with high and low empathic levels, it was found that the self-worth of players with high empathic levels was also high. It is clear that the signs of empathic behavior in sport should be different from those of empathic behavior in other environments(Erkus \& Yakupoglu, 2001).

The aim of empathy training is to improve the ability to empathize in person and ensure that every age group has good relationships with the individuals. The training to improve the empathic skills of the individual focuses on the development of emotional and cognitive skills, including empathic reactions; it also includes cognitive elements such as recognizing, evaluating and naming emotions that are necessary for the empathic phase (Pecukonis 1990, Kalliopuska, 1992). It is emphasized that this new experience will enable the person to realize that $\mathrm{s} /$ he has created himself in the life of the person and that the happiness of the individual and the society will be ensured by multiplying these moments by emanating from all the studies made and reaching a meaningful life for the person who listens and understands when the person listens and understands them in the empathetic attitude and behavior. Then, we can say that empathy is an attitude that all kinds of related people should do (Okvuran, 1994). Together with physical movements and sports, people do not only provide technical skills but also learn to respect other people and their different qualities by recognizing them (Camliyer \& Camliyer, 2001). Yilmaz and Sahinkaya (2010) found that empathic tendency levels differ according to gender in their research. This is thought to be due to the fact that in terms of gender variables women are associated with having a relatively more emotional structure than men.

Effective communication is one of the important needs for modern society to live in harmony. In order to be able to communicate well with the immediate surroundings, it is necessary to understand what they feel in their good or bad moments and to maintain consistency in their relationship in this context. This will increase the success of people in daily life. In this context, the empathy that enables people to live together has become a very important event. As in daily life, empathy has gained importance in the name of success in sports and increasing communication. Exercise has a significant effect on empathy.

Empathy lies in the presence of human beings. Some researchers argue that empathy can be earned later. But it is known that a situation that exists in humans actually changes according to the environmental conditions as he/she grows. The sedentary, which started to exercise with the change of the social environment, was conducted to investigate the effects of sport on empathic tendency levels.

\section{Method}

\subsection{The Model of the Study}

In the study conducted to investigate the effect of regular sports activities on the empathic tendency level of women; one group was planned as pretest-posttest. The aerobic-dance exercise program was administered for 60 minutes a day for 3 days a week for 8 weeks; The Empathic Tendency Scale (ETS) was applied twice, before and after the completion of aerobic exercise program.

\subsection{Population and Sample}

A total of 178 healthy adult women participated in the study as a volunteer. They were divided into groups: according to Marital Status ( $\mathrm{n}_{\text {single }}=84, \mathrm{n}_{\text {married }}=94$ ) and Business Status ( $\mathrm{n}_{\text {not working }}=121, \mathrm{n}_{\text {working }}=57$ ). 


\subsection{Data Collection Tools}

The Empathic Tendency Scale (ETS) was developed by Dokmen (1988) and it has been used as data collection tool in order to measure the empathy potential of individuals at daily life in this study.

\subsubsection{Empathic Tendency Scale (ETS)}

The Empathic Tendency Scale (ETS) was developed by Dokmen (1988). It is a Likert-type scale, consisting of 20 questions and grading from 1 to 5 for each question. 3,6,7,8,11,12,13,15. the questions are collected in reverse and the total score is reached. The minimum score to be taken from the scale is 20 and the maximum score is 100 . The total score expresses the empathic tendency scores of the subjects. The high score indicates that the empathic tendency is high while low indicates that the empathic tendency is low. (ETS) It was applied by Dokmen (1988) to a group of 70 students twice, by a three-week call, with a re-measure of the scale. The reliability obtained from this practice is 0.82 . The scales between the scores of the subjects' single and double items were found to be 0.86 . The validity of the scale was found to be 0.68 . The reliability coefficient calculated by Cronbach Alpha for the study group of the scale was found to be 0.72 . The validity and reliability study of the scale was conducted by Dokmen (1988).

\subsection{Analysis of Data}

Statistical Package for Social Sciences (SPSS) 20.00 software was used in the analysis of the data obtained from the research. In the analysis and interpretation of the data, the single sample Kolmogorov-Smirnov test was used to determine whether the sedentary women had normal scatter characteristics before testing the empathic skill levels according to various variables. A T-test was used to determine the difference between the pre-post test scores obtained from the Empathic Tendency Scale. For the statistical significance, the mistake level was taken as 0.05.

\section{Findings}

In this section, Empathic Tendency Scale (ETS) fulfilled over totally 178 healthy adult women who participated as Marital Status $\left(\mathrm{n}_{\text {single }}=84, \mathrm{n}_{\text {married }}=94\right)$ and participated as Business Status ( $\left.\mathrm{n}_{\text {not working }}=121, \mathrm{n}_{\text {working }}=57\right)$, in this study. Their score averages obtained before and after 8-week aerobic-dance exercise program from Empathic Tendency Scale. There are shown in the following tables.

Table 1. Empathic tendency pretest-posttest scores according to participants' marital status and job status variable

\begin{tabular}{|c|c|c|c|c|c|c|c|}
\hline \multirow{3}{*}{ Variables } & \multirow{2}{*}{\multicolumn{3}{|c|}{ Groups }} & Pre-Test & Post-Test & & \\
\hline & & & & $\mathrm{MN} \pm \mathrm{SD}$ & $\mathrm{MN} \pm \mathrm{SD}$ & $\mathrm{t}$ & $\mathrm{P}$ \\
\hline & Marital Status & Single & $(n=84)$ & $56,95 \pm 26,23$ & $70,41 \pm 8,18$ & 4,76 & 0,001 \\
\hline \multirow{3}{*}{ Empathic Tendency } & \multirow{3}{*}{ Business Status } & Married & $(n=94)$ & $61,89 \pm 27,58$ & $74,50 \pm 9,52$ & 4,74 & 0,001 \\
\hline & & Not Working & $(n=121)$ & $60,90 \pm 25,75$ & $72,50 \pm 9,30$ & 5,14 & 0,001 \\
\hline & & Working & $(n=57)$ & $56,72 \pm 29,49$ & $72,70 \pm 8,81$ & 4,36 & 0,001 \\
\hline
\end{tabular}

It was observed that there was a statistically significant difference between the empathic tendency pre-test and post-test scores according to the participants' marital status and job status variable $(\mathrm{p}<0,05)$. It was also found that the mean scores of empathic tendency post-test scores increased according to the Marital Status and Work Status variable.

Table 2. Multiple Comparisons Test for Comparing Empathic Tendency Scores According to Age Variables of Participants

\begin{tabular}{|c|c|c|c|c|c|}
\hline \multirow[t]{2}{*}{ Variables } & \multicolumn{5}{|c|}{ Difference between the averages (I-J) } \\
\hline & (I) Age & (J) Age & & Std. Mistake & $\mathrm{P}$ \\
\hline \multirow{6}{*}{ Empathic Tendency Pre-test } & $17-20$ & $21-24$ & 1,7561 & 2,0065 & 1,000 \\
\hline & & $24+$ & $-3,8739$ & 1,6410 & 0,058 \\
\hline & $21-24$ & $17-20$ & $-1,7561$ & 2,0065 & 1,000 \\
\hline & & $24+$ & $-5,6300^{*}$ & 1,7027 & $0,003 *$ \\
\hline & 24 and older & $17-20$ & 3,8739 & 1,6410 & 0,058 \\
\hline & & $21-24$ & $5,6300^{*}$ & 1,7027 & $0,003 *$ \\
\hline \multirow{6}{*}{ Empathic Tendency Post-test } & $17-20$ & $21-24$ & $-5,9565$ & 6,0940 & 0,989 \\
\hline & & $24+$ & $-9,3024$ & 4,9838 & 0,191 \\
\hline & $21-24$ & $17-20$ & 5,9565 & 6,0940 & 0,989 \\
\hline & & $24+$ & $-3,3459$ & 5,1714 & 1,000 \\
\hline & 24 and older & $17-20$ & 9,3024 & 4,9838 & 0,191 \\
\hline & & $21-24$ & 3,3459 & 5,1714 & 1,000 \\
\hline
\end{tabular}

Multiple Comparison for Comparing Empathic Tendency Points According to Age Variables of Participants, the difference between the pre-test averages in the test results was found to be statistically significant only between 21-24 
years and 24 years and above $(\mathrm{p}<0,05)$. There was no significant difference between the post-test averages $(\mathrm{p}<0,05)$.

Table 3. Multiple Comparisons Test for Comparing Empathic Tendency Scores According to the Number of Children in the Participants

\begin{tabular}{|c|c|c|c|c|c|c|}
\hline Variables & & $\begin{array}{l}\text { (I) Number of } \\
\text { children }\end{array}$ & $\begin{array}{l}\text { (J) Number of } \\
\text { children }\end{array}$ & $\begin{array}{l}\text { Difference between the } \\
\text { averages (I-J) }\end{array}$ & $\begin{array}{l}\text { Std. } \\
\text { Mistake }\end{array}$ & $\mathrm{P}$ \\
\hline \multirow{6}{*}{$\begin{array}{l}\text { Empathic } \\
\text { Pre-Test }\end{array}$} & \multirow{6}{*}{ Tendency } & None & $1-2$ & $-3,8604^{*}$ & 1,5818 & 0,047 * \\
\hline & & & 3 and older & $-3,1935$ & 1,7973 & 0,232 \\
\hline & & $1-2$ & none & $3,8604^{*}$ & 1,5818 & $0,047 *$ \\
\hline & & & 3 and older & 6669 & 2,0074 & 1,000 \\
\hline & & 3 and older & none & 3,1935 & 1,7973 & 0,232 \\
\hline & & & $1-2$ &,- 6669 & 2,0074 & 1,000 \\
\hline \multirow{6}{*}{$\begin{array}{l}\text { Empathic } \\
\text { Post-Test }\end{array}$} & \multirow{6}{*}{ Tendency } & None & $1-2$ & $-7,7416$ & 4,7345 & 0,311 \\
\hline & & & 3 and older & $-5,1755$ & 5,3796 & 1,000 \\
\hline & & $1-2$ & none & 7,7416 & 4,7345 & 0,311 \\
\hline & & & 3 and older & 2,5660 & 6,0084 & 1,000 \\
\hline & & 3 and older & none & 5,1755 & 5,3796 & 1,000 \\
\hline & & & $1-2$ & $-2,5660$ & 6,0084 & 1,000 \\
\hline
\end{tabular}

Multiple Comparisons for Comparing Empathic Tendency Scores According to Participants' Number of Children Variable, the test results showed that the difference between pre-test averages was statistically significant only among those who did not have children and those who had 1-2 children $(p<0,05)$. There was no significant difference between the post-test averages $(\mathrm{p}<0,05)$.

\section{Discussion}

This study was the first study to determine the empathic tendency levels of sedentary women and to examine the effect of exercise after the aerobic exercise program. In previous researches, it was observed that more sports groups and non-sports groups were compared and examined in terms of various variables.

In order to investigate the effects of regular sports activities on the empathic tendency level of women, a meaningful result was found in comparing the pre and post test scores according to the participants' marital status and job status $(\mathrm{p}<0.05)$. After the exercise program, both single and married women; empathic tendency levels of both working and non-working women were found to increase in the pre-test and post-test averages.

When the participants' results were analyzed according to the age variable, there was a statistically significant difference between the groups in the pre-test averages. As a result of the multiple comparisons, the difference between the pre-test scores was found to be between 21-24 years and in women over 24 years of age $(\mathrm{p}<0.05)$.

Age seems to be effective on the empathic tendency. There is no difference between the groups in the post-exercise comparisons and it is thought that all groups of exercises have an influence on the empathic tendencies.

According to the number of children, the difference between pre-test averages in the results of empathic tendency scores was found to be statistically significant only among those who did not have children and those who had 1-2 children $(\mathrm{p}<0,05)$. There was no significant difference between the averages after the exercise program $(\mathrm{p}<0,05)$.

Erkus \& Yakupoglu (2000) found that soccer players had lower empathic skills than basketball and handball players. Korkmaz (2001) investigated the gender difference of girls and boys in physical education and sports school. As a result, there was no significant relationship between gender differences and empathic skills of students. In his study with physical education and sports college students, Erkmen (2007) found that women had a higher average empathic tendency than males.

Besides, Ayas et al., (2016) carried out to compare the empathic tendency levels of sports sciences faculty students in terms of different variables and to determine whether there is a significant difference or not. It was determined that the empathic tendency score of the Sports Sciences Faculty students are high. But other parameters such as sex, age, department of education, educational level of mother and father do not affect the main conclusion about emphatic tendency levels of the students.

Mete \& Gercek (2005) conducted a survey of 192 students from Dokuz Eylul University School of Nursing in order to investigate the effect of the Probing Based Learning (PBL) method on the empathic tendencies and skills of the students of Nursing School. In this study, the Empathic Tendency Scale (ETS) and the Empathic Skill Scale (ESS) were used to assess students' empathic tendencies and abilities, and the Introducing Knowledge Forum was used to determine their socio-demographic characteristics. As a result of the research, the empathic tendency levels of the students increased as their class moved up to high level. Ercoskun (2005) found that gender factors differed in the tendency to empathize with empathic skills when examining the effects of empathic skills on classroom teaching students. It turned out that girls 
tend to have higher empathy than boys.

Gini et al., (2007) also investigated the violent behavior of adolescents with 142 girls and 176 male adolescents. As a result, it was found that adolescents with low empathic levels used violence. Kemp and et al. (2007) examined the relationship between empathic levels of adolescents and family support and antisocial behavior. A total of 823 students from 11-14 age group participated in the research and as a result, it was seen that the empathic levels of the adolescents who were not fully supported by the family were low and therefore they were in more aggressive behavior than the other peers.

When the studies are examined, it is seen that there is no study on the effect of aerobic exercise and its derivatives on the empathic tendency. Therefore, considering that exercise increases social communication, social reconciliation, and group dynamics, it is possible to examine whether aerobic exercise and its varieties contribute to empathic inclination by studying larger groups. As a result; the aerobic exercise program has a positive effect on empathic tendency levels in sedentary women.

\section{References}

Ayas, E., Inan, H., Kartal, M., \& Gacar, A. (2016 ). Comparison of Empathy Levels of University Students in Sports Education in Terms of Different Variables. International Journal Of Social Science, 53, 459-466. https://doi.org/10.9761/JASSS68822

Barnett, M. A. (1990). Empathy and related responses in children. In Empathy and its Development. (pp. 146-163). Cambridge: Cambridge University Press.

Barut, Y. (2004). Examination of Levels of Empathic Tendency and Conflict Tendency of Teachers Working in Secondary Education Institutions in Terms of Some Variables. XIII. National Education Sciences Congress. Malatya.

Bellous, J. (2001). Considering Empathy: Some Preliminary Definition. Retrieved 01 05, 2017, from http://www.mcmaster.ca/mjtm/bellous.htm

Camliyer, H., \& Camliyer, H. (2001). Child Movement Education and Game in the Integrity of Education. Manisa: Emek Printing.

Cetin U. F. (2010). Religiosity end empathy relationship among high school level teenagers. (Unpublished Master's Thesis), Süleyman Demirel Universty, Institute of Social Sciences, Isparta, Turkey.

Cuceloglu, D. (1994). Again Human,People (8. ed.). Istanbul, Remzi Bookstore.

Davis, M. H. (1983a). Measuring Individual Differences in Empathy: Evidence for a Multidimensional Approach. Journal of Personality and Social Psychology, 44(1), 113-126. https://doi.org/10.1037/0022-3514.44.1.113

Davis, M. H. (1983b). The effects of dispositional empathy on emotional reactions and helping: A multidimensional approach. Journal of Personality, 51(2), 167-184. https://doi.org/10.1111/j.1467-6494.1983.tb00860.x

Dokmen, U. (1988). Measurement of Empathy with a New Model-Based and Development with Psychodrama. Ankara University Faculty of Education Sciences Journal, 21 (1-2) 155-190.

Dokmen, U. (1995). Communication Conflicts and Empathy. $2^{\text {nd }}$ Edition. Sistem Publishing, Istanbul,Turkey.

Eisenberg, N., \& Miller, P. A. (1987). The relation of empathy to prosocial and related behaviors. Psychological Bulletin, 101, 91-119. https://doi.org/10.1037/0033-2909.101.1.91

Eisenberg, N., \& Strayer, J. (1987). Empathy and Its Development. Cambridge University Press, Cambridge.

Eisenberg, N., \& Strayer, J. (1990). Empathy and Its Development. Cambridge University Press, Cambridge.

Ercoskun, M. H. (2005). Examination of Empathic Skills of Classroom Teaching Students in Terms of Diverse Variables. (Unpublished Master's Thesis), Ataturk University, Institute of Social Sciences, Erzurum, Turkey.

Erkmen, G. (2007). Comparison of the Empathic Trends of the Students at Selcuk University Faculty of Physical Education and Sports with the Leadership Behavior Preference to Sport. (Unpublished Master's Thesis), Selcuk University, Health Sciences, Konya, Turkey.

Erkus, A., \& Yakupoglu, S. (2000). Empathy Measure in Sports Environment (SEM) Development Work. VI. Sports Science Congress Book (pp. 139). Ankara, Turkey.

Erkus, A., \& Yakupoglu, S. (2001). Empathy Measure in Sports Environment (SEM) Development Work, Hacettepe J. Of Sports Sciences 2001, 12(1), 22-31. 
Feshbach, N. D., \& Roe, K. (1968). Empathy in Six and Seven Year Olds. Child Development, 39, 133-145. https://doi.org/10.2307/1127365

Gini, G., Albiero, P., Benelli, B., \& Altoe, G. (2007). Does Empathy Predict Adolescents' Bullying and Defending Behavior? Aggressive Behavior, 33, 467-476. https://doi.org/10.1002/ab.20204

Hogan, R. (1969). Development of an empathy scale. Journal of Consulting and Clinical Psychology, 33, 307-316. https://doi.org/10.1037/h0027580

Kalliopuska, M. (1992). Holistic empathy education among preschool and school children. International Scientific Conference Comenius Heritage and Education of Man (p. 1-20). Prague.

Kemp, R. A. T., Overbeek, G., Wied, M., Engels, R., C. E. M., \& Scholte, R. H. J. (2007). Early Adolescent Empathy, Parental Support, and Antisocial Behavior, The Journal of Genetic Psychology, 168(1), 5-18. https://doi.org/10.3200/GNTP.168.1.5-18

Kohlberg, L. (1969). Stage and sequence: The cognitive development approach to socialization. In D. A. Goslin (Ed.). Handbook of socialization theory (pp. 347-480). Chicago, IL, Rand McNally.

Korkmaz, N. (2001). The comparison of the Empathetic Skills of the Students of Uludag University Physical Education and Sports Department by Gender. II.International Sports Psychology Symposium (pp.18). Izmir, Turkey.

Mete, S., \& Gercek, E. (2005). Examination of Empathic Tendencies and Skills of Nursing Students Trained by PBE Method. C. U. Journal of Nursing School Book, 9(2), 11-17.

Okvuran, A. (1994). The Importance of Creative Drama Education in Contemporary Human Creation and Its Impact on Empathy Skills and Empathic Tendency Levels, Journal of Educational Sciences, 27.

Pecukonis, E. V. (1990). A cognitive/ affective empathy training program of ego development in aggressive adolescent females, Adolescence, 25(97), 59-76.

Reeves, T. G., Bowman, J. T., \& Cooley, S. L. (1989). Relationship between the Client's Moral Development Level and Empathy of the Counseling Student. Counselor Education and Supervision, 28, 299-304. https://doi.org/10.1002/j.1556-6978.1989.tb01120.x

Roßnagel, C. (2004). Cognitive load and perspective taking: applying to verbal communication. European Journal Social Psychology, 30, 429-445. https://doi.org/10.1002/(SICI)1099-0992(200005/06)30:3<429::AID-EJSP3>3.0.CO;2-V

Smith, K. D., Keating, J. P., \& Stotland, E. (1989). Altruism reconsidered: The effect of denying feedback on a victim's status to empathic witnesses. Journal of Personality and Social Psychology, 57(4), 641-650. https://doi.org/10.1037/0022-3514.57.4.641

Solak, N. (2011). Examinaton of the relationship between the levels of agression and levels of the emphatic tendencies of secondary education students who do sports and those who do not do sports (the Çorum case). (Unpublished Master's Thesis), Gazi University, Institute of Educational Sciences, Ankara, Turkey.

Voltan-Acar, N. (1994). Therapeutic Communication: Interpersonal Relationships. Ankara, Safak Printing.

Winnet, A. (2001). Empathy In Communication, http:/www.selfgrowth.com, Self Improvement Online, Inc. 2001

Yllmaz, S., \& Sahinkaya, N. (2010). The Relationship Between The Methods Teachers Use Against The Misbehaviour Performed in The Classroom and Emphatic Tendencies Of Teachers. Procedia Social And Behavioral Sciences, 2932-2936. https://doi.org/10.1016/j.sbspro.2010.03.443

\section{Copyrights}

Copyright for this article is retained by the author(s), with first publication rights granted to the journal.

This is an open-access article distributed under the terms and conditions of the Creative Commons Attribution license which permits unrestricted use, distribution, and reproduction in any medium, provided the original work is properly cited. 